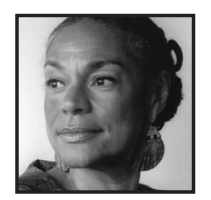

\title{
Commentary Portraiture Methodology: Blending Art and Science
}

\author{
Sara Lawrence-Lightfoot
}

\begin{abstract}
In this interview, Sara Lawrence-Lightfoot describes the genesis of the portraiture methodology and how it has developed over the past three decades. Portraiture seeks to blend art and science, bridging empiricism and aestheticism. It draws from a wide variety of phenomenological and narrative traditions. One of the ways in which it is distinct from other research methodologies is in its focus on "goodness"; documenting what is strong, resilient, and worthy in a given situation, resisting the more typical social science preoccupation with weakness and pathology. Dr Lawrence-Lightfoot also explains the work she does with her students at Harvard and gives examples of their research projects. She finishes by giving words of advice to those researchers interested in using the portraiture methodology.
\end{abstract}

1) You have been interested for a long time in research methodologies and more specifically in a form of artful inquiry that you developed called "portraiture." Can you define portraiture and how this methodology evolved?

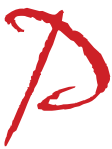
ortraiture is within the realm of qualitative inquiry. It's a phenomenological methodology, but it is distinctive in that it is the first social scientific methodology that is explicit in blending art and science, bridging empiricism and aestheticism. It cares deeply about rigorous empirical description, but it also cares a lot about the artfulness of the doing of it and the displaying of it... the ways in which portraiture is written, composed, developed, and presented to an audience. The other way in which it's distinctive is that it is very much written for multiple and diverse audiences. It is intentionally inclusive. That is, it is not just written 
for members of the Academy, for my colleagues and my students, but for broader, eclectic audiences. The idea is to get people interested in thinking about important questions in complicated, grounded, thoughtful ways. And so, it is intentionally provocative. It hopes to invite a response from the reader. As an interpretive narrative, portraits aspire to being beautifully and evocatively written, deep and compelling stories.

Another way in which portraiture is distinct from other qualitative inquiries is in its explicit focus on "goodness." And by that I don't mean that it tries to idealize or romanticize human experience or social reality, but rather, that it is a counterpoint to so much of social science inquiry that has traditionally been preoccupied with pathology, with searching out what is wrong and trying to remedy the wrongs. I certainly understand that impulse in social scientists. That is, "if we look at the problem deeply, find a way to document and measure it, maybe we will be able to actually do something about solving it." But, this kind of inquiry often bleeds into a preoccupation with pathology, and often devolves into blaming the victim. Portraiture very purposefully says we're going to try to understand what's worthy and strong; always recognizing of course that goodness is inevitably laced imperfection. After all, every human endeavour possesses imperfection and weakness. In another sense, we want to document what's strong and worthy, in great detail so that we might figure out ways of transporting those "goods," that goodness, to other settings and transforming them as well. That begins to describe some of the central tenets of portraiture.

(1)) Can you talk about the key theorists who have helped you to nurture the idea of portraiture?

I think all of the scholars and theorists who speak from a phenomenological perspective, trying to understand people's experiences and meaning-making, seeking to document the processes of human encounter in context. But l've also been drawn to the beautiful work of novelists and poets. Even those people whose work is positivistic or structuralist have offered me an important counterpoint, a way in which my work can be in contradistinction and discussion with other people's work. So, who do I think of? I think about Jerome Bruner's body of work. I think about Oliver Sacks' work, a neurologist and storyteller whose work documents human experience from a phenomenological perspective. I think about Howard Gardner, even Piaget, in terms of trying to understand in great detail how people see and perceive things, particularly children. And, of course, Dewey and his work. My favourite book of all time is "Art as Experience." It is a very dense big book, but everything in it has meaningful 
connections to the roots of portraiture. Then there is Elliot Eisner and Clifford Geertz, both of them important influences on my work. All of these theorists and researchers have been working this fertile terrain, searching for ways to bring art, science, and humanism together.

\section{(1)) When did you first start practising portraiture and what did you learn from this?}

My first efforts at portraiture were related to research for my book, "The Good High School," published in 1983. I spent about three years examining the character and culture of high schools across the country. I had been well trained as a sociologist in both quantitative and qualitative methods; my dissertation had used mixed methods. In fact, I loved the kind of discreteness and clarity of quantitative research. But, I found that the things that I wanted to study, the questions I wanted to ask, the problems I wanted to pursue, could not be answered through quantitative measurement. I had also been well trained in ethnography, but when I went into these high schools, I realized that these places were amazingly theatrical environments and that I needed to find a way to describe and decode what I was seeing. And I thought: I need to really figure out a deeper and more nuanced way to draw these environments, to portray their character, to capture their culture. My initial foray into the field was part of a project that originated with Dædalus, the Journal of the Academy of Arts and Sciences, where a seminar of scholars from different disciplines were focused on trying to understand the character of high schools and the nature of adolescence, the ways in which these institutions served or disserved the developmental needs of adolescents. I was sent out into the field by this group, along with Robert Coles and Philip Jackson, to try to capture the high school scene, and I was the one who said, "Why don't we call them portraits?" Since this was very exploratory, I wanted to release us from the protocols and constraints of traditional research strategies. When Dædalus was published and there was a huge response to these pieces, I decided to continue the work, which ultimately resulted in "The Good High School." As I collected data, I tried in a very self-conscious way (in the best sense of the word) to really understand what I was doing and how I was working. I was working on two planes. I was trying to portray these schools in great depth and write portraits, but I was also trying to really describe to myself the methodology that I was in fact pioneering. And so, "The Good High School" was my initial effort at doing portraiture and the introduction to that book was my first attempt to describe the methodology. 


\section{1)) Can you describe generally the process you use to implement portraiture?}

I always tell my students that they should begin framing their research by identifying their burning question. What is it that you are really curious about? What do you want to know and pursue? What truly interests you? Identifying the burning question should come before asking, "How am I going to study this? What are the methodologies I'm going to use? What's the literature I'm going to cite?" It's good to start with the thing that really grabs you, troubles you, puzzles you. And then you move from that to designing a researchable question. As we make the move from the burning question to the researchable question, inquiry always narrows. In some ways, it may feel impoverished because there are a lot of important questions and problems that cannot be answered through empirical research. Usually, when I get to the point in the process where I have identified a research question, I begin to search out the relevant literature and ask myself, "What is the broader discourse saying? Where might my work fit into the larger scholarly and public conversations?" I'm always interested in asking the question that hasn't been asked before or asking the question that remains unanswered.

In lots of ways portraiture resembles most kinds of good, deep, layered qualitative inquiry. You're using in-depth interviews over time, observations and participant observation; you're using document analysis and mapping the context. And you are, of course, creating relationships with the people who you are interviewing and whose lives you're trying to capture, that are trusting and communicative and respectful; you are working on creating and sustaining authentic encounters. The relational dimensions and dynamics of this work are very important. I often say to my students that this is not a methodology that poses "gotcha" questions. You are not a journalist trying to trip up or expose the other person; you are not out to pursue that person's shadowy places. This is not about that. This is about seeking to explore and understand. We go deeply into this individual's story, hoping to capture more universal themes. The work is deep and penetrating, but it must never be voyeuristic. Those of us who are experienced portraitists know very well that line when our inquiry begins to become voyeuristic, and we try our best never to cross that line.

When I'm out in the field I'm trying to document as much as I can; nothing is too trivial to record. I'm trying to capture the context, not just the physical context, but also the socio-cultural context. Context, after all, is the best resource for interpreting the talk and actions of people. We do not know the intentions, motivations, and meanings attached to people's behaviors unless we see them embedded in context. As a portraitist, I am also interested in mapping the aesthetic context that surrounds the person or the institution, seeking to capture sensory dimensions, the visual, the tactile, 
the auditory. I am always "listening for" the metaphors, the images, the allusions people use, and the repetitive refrains that lace their talk. Then the portraitist triangulates the data from these multiple sources.

\section{1)) How do you refute any skepticism about the rigor or validity of portraiture?}

I have mostly stopped refuting or defending my methods and approaches. I regard it as a waste of my energy to even try. Originally, when I started doing this work, it felt audacious and very risky. I did not have tenure here at Harvard and all of my colleagues, even those who thought I was doing wonderful and valuable work, advised me to do a more traditional research: a project that followed the tenets of positivist approaches where there was already consensus over what counted as scholarly or rigorous. I certainly could have done that, but I had a sense that the questions I was seeking to answer through my work were not answerable through the methods and measurements of traditional genres of scholarship. I also sort of knew even then that we researchers and academics do our best work when we lead with our gifts, with the ways in which we might have a unique and singular perspective. So I resisted the warnings and worries of my senior academic colleagues and decided to proceed. In those days I did spend a lot of time, not so much defending portraiture, but, rather, finding a way of not being, or seeming, defensive when I talked or wrote about it. Instead I always wanted to be affirmative and clear.

The reason I wrote the book, "The Art and Science of Portraiture," was because I wanted to say there is a rigorous methodology here. Today portraiture is being taught all over the country using my methodology text. And many of my former students are teaching methodology courses in colleges and universities where portraiture is part of the qualitative research sequence.

In terms of my career, which has been here at Harvard (I'm now in my 44th year!), I really don't have any time left in my life to be worried about defending portraiture as a valid research methodology or refuting other people who might be skeptical of its science and usefulness. From the very beginning I was very sure that I didn't want to spend a lot of time in a defence posture. Rather, I wanted to be precise and clear about methods and uses of portraiture in an affirming, productive way that says this is one among many social science methodologies that is appropriate to use in certain contexts. 
1)) In your classes at the Harvard School of Education, what kinds of things do you have students do to acquire the skills of portraiture?

I teach a course called the "Art and Science of Portraiture," a seminar designed for advanced graduate students who have already had a lot of training in research design and methodology, both quantitative and qualitative. We read a number of qualitative and narrative works as well as portraits in the course, some of them written by me and some by other social scientists. We begin by reading "Souls of Black Folk" by W. E. B. Du Bois, more of a socio-historical mural than a portrait, where Du Bois paints himself into a southern, segregated, racial landscape as a rural school teacher and it's very interesting. We read essays by Lightman, an MIT scientist who writes about the fusion of art and science. And we read and look critically at Geertz, Eisner, William James, and Dewey, people whose work has been historically related to portraiture and humanistic, artful inquiry. From the very beginning of the course I ask students to identify a question, a burning question, and then a researchable question. Students begin their fieldwork early in the semester collecting data, writing impressionistic memos and emerging hypotheses, conducting data analyses, and composing their interpretive narratives.

One of the things that's very effective about the course is that by the end when people have developed their portrait, we all read them, and in the last three or four sessions of the seminar one critic is speaking to the portrait of another individual. The portraitist really doesn't get to say anything...maybe five minutes of remarking about something interesting, insightful, and compelling or problematic about doing the work that they want to let us know about. It is the critic who holds forth for about 30 minutes, a very probing, thoughtful, and discerning critique of the piece. And then we all come into the conversation so that people get a response to the work that's very vivid and very specific, and that is a rare kind of exchange in university classes. It is really a wonderful experience in the end.

\section{4)) Can you give an example of one?}

There are so many wonderful examples. One portrait, written by someone who was born in Russia and emigrated from there when she was eight years old, focused on the pedagogy of a teacher in a Russian mathematics school in Newton, Massachusetts. Another portrait by an African-American student who grew up in New Orleans, whose family was displaced by Hurricane Katrina, did an extraordinary piece on a class in literature and poetry that he was teaching to incarcerated men in a maximum-security 
prison. The student had been a public school teacher in a poor Black neighbourhood in Baltimore, and had witnessed the terrible impact of the "school to prison pipeline." Another portrait, by a woman who was a former science teacher interested in environmental activism, focused on a young community organizer in East Boston who was leading a youth group of high school students who were designing campaigns to clean up the city landscape around them. Over the years, students have produced portraits of individuals, organizations, relationships, processes, and even concepts. Many of their pieces have been published in social science and educational journals.

\section{(1)) What does the discussion sound like when the critic discusses the piece?}

First of all, my suggestion to the critics is that they not try to comment on everything, and that they be very specific. They need to be able to show us in the text to what they are referring and they also need to be constructive. "What would make this a better piece?" Some of the critiques focus exclusively on methodology, looking at the interview protocols and strategies, the observational data, the documents, how these lenses and data are triangulated. Others focus on the content of the narrative. "What is this about, what's the problem being discussed, what did we learn from this piece?" It's more content rich, substantive, purposefully trying to mine the major issues that this portrait allows us to see with more clarity and insight. Still other critiques resemble a literary analysis. The critic might say, "I'm really going to look at this narrative as a piece of literature; focusing on the aesthetic presentation, the arc of the narrative, and so forth." People enter into their critiques in very different ways, but in order for a 20- or 30-minute critique to be useful, it has to be relatively narrowly circumscribed.

(1))

What kinds of things would you suggest to researchers who are keen to use a portraiture methodology?

Sometimes when doctoral students come in to see me in my office they will say, "I want to use portraiture in my dissertation." And I say, "That's the wrong way of going about it. In other words, tell me what you're interested in, tell me what your question is, and let's talk about what methodology would be the best way to pursue that question." The first thing is that one never begins with a commitment to a methodology without first designing a question. If the researcher asks a question appropriate for portraiture then they need to bring all the diligence, discernment, and rigor to bear that they've learned in their other research methods training, but they also have to be open to the ways in which some of those things do not work in portraiture. Portraiture is in part 
about following the rules of good research, but also in part about breaking the rules of traditional positivist research. You have to figure out a way to enter where you both appreciate good social science research and find ways in which, at least for this project and this question, those are not appropriate strategies and those don't allow us to see, perceive, understand, and document in the ways that we need to.

I think that most people who want to do portraiture have an artistic impulse in them. They want to tell a rich, comprehensive, deep story and they want to speak to broader audiences beyond the Academy.

\section{4)) Do you have any other comments you'd like to add about artful inquiry?}

I think that more and more it's becoming part of the lexicon, repertoire, and canon of social scientific inquiry. As we use it more, as we find a way to use it for the right things, in the right way, as we practice it, rather than try to defend it, as we appreciate the other kinds of research methodologies that are out there for what they do, it begins to become a part of the continuum of methodologies useful to social scientists for studying human experience and social phenomena. Just like I believe that education without artistic training and experience is an impoverished education, so too I believe that the University and Academy should allow for this kind of artistic expression. It's nice to be the standard bearer of that, but it's also nice to pass it along to other people. One of the things about teaching portraiture and then witnessing and reading the work of my students is that the methodology continues to develop, be refined, and diversified. I see that as a wonderful advance in the work.

\section{References}

Dewey, J. (1934). Art as experience. New York: Perigee.

Du Bois, W. E. B. (1903). Souls of Black folk: Essays and sketches. Chicago: A.C. McClurg and Co.
Lawrence-Lightfoot, S. (1983). The good high school: Portraits of character and culture. New York: Basic Books.

Lawrence-Lightfoot, S., \& Davis, J. H. (1997). The art and science of portraiture. San Francisco: Jossey-Bass. 


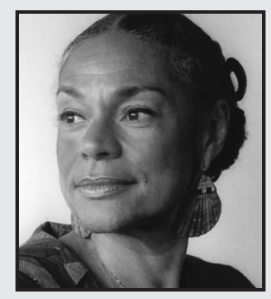

Sara Lawrence-Lightfoot, a MacArthur prize-winning sociologist, is the Emily Hargroves Fisher Professor of Education at Harvard University, where she has been on the faculty since 1972. Educator, researcher, author, and public intellectual, Lawrence-Lightfoot has written 11 books, including The Good High School: Portraits of Character and Culture (1983), which received the 1984 Outstanding Book Award from the American Educational Research Association, and The Art and Science of Portraiture (1997) (with Jessica Hoffmann Davis), which documents her pioneering approach to social science methodology. She has served on many professional and scholarly committees and boards of directors, and received numerous awards, including 30 honorary ones from colleges and universities in the United States and Canada. Upon her retirement, she will be the first African-American woman in Harvard's history to have an endowed professorship named in her honor. 